\title{
Transesterification of phenylalanine by means of chymotrypsin in a continuous fixed bed reactor
}

\author{
Christine Moresoli, Erwin Flaschel and Albert Renken \\ Institut de génie chimique, Ecole Polytechnique Fédérale de Lausanne, \\ Lausanne, Switzerland
}

\begin{abstract}
An enzymic transesterification was carried out in a continuously operated fixed bed reactor. The reaction system consisted of immobilized $\alpha$-chymotrypsin (E.C. 3.4.21.1) catalysing the transfer of the L-phenylalanine radical from the racemic propyl ester to 1,4-butanediol, yielding L-phenylalanine 4-hydroxybutyl ester. The desired reaction was accompanied by alcoholysis due to the presence of I-propanol liberated during the reaction and by hydrolysis of both the propyl and the hydroxybutyl ester. The problem of shifting $\mathrm{pH}$ during the reaction due to ester hydrolysis was overcome by adjusting the initial $\mathrm{pH}$ of the substrate feed solution appropriately in order to obtain a sufficiently high buffer capacity provided by the free amino group of the esters. Thus, it was possible to work with shifting pH, an obvious disadvantage for operating reactors of low backmixing for this kind of reaction system. The overall reaction scheme was characterized by the appearance of a maximum ester yield as a function of the operating time in case of batch reactors. Surprisingly, the yield was found to become constant as a function of space-time for continuous operation due to a steeper $\mathrm{pH}$ drop. The maximum productivity achieved with respect to the hydroxybutyl ester was about $65 \mathrm{~mol}^{-1} \mathrm{l}^{-1}$ referred to the catalyst volume.
\end{abstract}

Keywords: Enzyme catalysis; immobilized $\alpha$-chymotrypsin; transesterification; continuous fixed bed reactor

\section{Introduction}

The application of enzymes for the synthesis of organic compounds has received considerable attention in the past decade. ${ }^{1}$ Their high specificity and catalytic efficiency render enzymes very attractive for organic chemists, in spite of their high cost and the limited domain of operational conditions under which they may function. However, immobilized enzymes permit the catalyst to be reused or even to be used in a continuously operated reactor, thus reducing significantly the cost of enzymatic processes. An additional advantage of immobilization, in the case of proteolytic enzymes, is the improved enzyme stability owing to reduced autohydrolysis. Immobilization, on the other hand, may result in modification of the enzyme structure and/or in masstransfer limitation due to film- and pore diffusion of substrates and/or products to and from the active sites. ${ }^{2}$

Among the applications considered for enzymic syn-

Address reprint requests to Dr. Renken at the Institut de génie Chimique, Department de Chimie, EPFL-Ecublens, CH 1015 Lausanne, Switzerland.

Received 6 September 1990; revised 15 February 1991 theses, hydrolases have shown to be useful for the preparation of condensation products such as $\beta$-lactam antibiotics, esters, peptides, oligosaccharides, and glycerides. ${ }^{3}$ In these systems, hydrolases act like transferases owing to the formation of a covalent intermediate.

Serine proteases acting on esters are just one example. The mechanism of these enzymes involves the formation of an acyl-enzyme intermediate, with the release of the alcohol and the subsequent decomposition of the intermediate under the action of a nucleophile. The type of nucleophile used determines the structure of the product obtained. If it is a nonprotonated amino group, the product is a peptide; if it is a hydroxylated compound, the product is an ester; and if it is simply water, hydrolysis yields the free acid. These observations have suggested that serine proteases, such as $\alpha$ chymotrypsin, could be used to catalyse the exchange of alcohol moieties of esters, leading to transesterification. In these reactions, the evolution of the yield of the transfer product with time is characterized by a maximum, because both esters, the substrate and the product, may undergo hydrolysis. For transesterification, a kind of kinetically controlled synthesis, the maximum yield of the transfer product may be easily obtained with immobi- 
lized enzymes, as suggested by Kasche et al. ${ }^{4}$ In a batch system, the reaction can be stopped at the maximum yield of the transfer product by removing the immobilized enzyme. Alternatively, in a continuously operated fixed bed reactor, the reaction can be stopped at the maximum yield simply by adjusting the space-time of the reaction mixture in the reactor.

In previous work, the transesterification of a racemic mixture of phenylalanine propyl ester (DL-PAPE) with 1,4-butanediol by means of soluble $\alpha$-chymotrypsin has been investigated. The optimization of the operating $\mathrm{pH}$ and the initial concentration of both DL-PAPE and 1,4-butanediol has been reported. The optimum referred to those conditions leading to a maximum productivity of the transfer product at $95 \%$ of its maximum yield. ${ }^{5}$ These conditions were a $\mathrm{pH}$ of 6.25 , a concentration of DL-PAPE of $200 \mathrm{mmol} \mathrm{I}^{-1}$, and a concentration of 1,4-butanediol of $2,000 \mathrm{mmol} \mathrm{l}^{-1}$, with a productivity of $22.8 \mathrm{mmol} \mathrm{g}^{-1} \mathrm{~min}^{-1}$. The kinetics of this reaction have also been studied. ${ }^{6}$ In this paper, the use of a continuous fixed bed reactor with immobilized enzyme is discussed.

\section{Methods}

\section{Materials}

Soluble $\alpha$-chymotrypsin ( $\alpha$-CT), E.C. 3.4.21.1, was obtained as a lyophilized powder from SIGMA (Type II, C4129). DL-Phenylalanine propyl ester (DL-PAPE) was obtained in the form of its hydrochloric salt. All other reagents were of analytical grade.

\section{Immobilization procedure}

Immobilized $\alpha$-chymotrypsin was obtained from Hoechst (Frankfort, Germany). The immobilization procedure consisted in fixing the enzyme on silica gel particles activated with glutardialdehyde. ${ }^{7}$

\section{Determination of particle size}

The particle size distribution of a sample of immobilized $\alpha$-chymotrypsin was measured by means of a laser particle sizer (Malvern, model 2600). The mean particle diameter, determined from its volumetric distribution, was $0.2 \mathrm{~mm}$.

\section{Enzyme activity}

The activity of immobilized $\alpha$-chymotrypsin was obtained by carrying out the hydrolysis of DL-PAPE with an initial concentration of $100 \mathrm{mmol} \mathrm{l}^{-1}$. The reactor, a stirred tank with a reaction volume of $25 \mathrm{ml}$, was kept at a constant temperature of $30^{\circ} \mathrm{C}$ and the $\mathrm{pH}$ maintained at 6.25 by means of controlled addition of $1 \mathrm{M} \mathrm{NaOH}$ solution. Estimation of the normalized operating time at a given yield of product, analyzed by acidimetry, for each of the two forms of enzyme gave the equivalent global activity of immobilized $\alpha$-chymotrypsin. Thus, a volume of $1.0 \mathrm{ml}$ of immobilized $\alpha$-chymotrypsin has the same activity as $0.24 \mathrm{mg}$ of soluble $\alpha$-chymotrypsin.

\section{Product analysis}

The products were analyzed by HPLC on a Nucleosil 7C8 column of $250 \mathrm{~mm}$ in length and with a diameter of $4.6 \mathrm{~mm}$. The eluent contained $10 \mathrm{~g} \mathrm{KH}_{2} \mathrm{PO}_{4}$ and $1 \mathrm{~g}$ tetrabutylammonium hydrogen sulfate per liter of aqueous solution. The $\mathrm{pH}$ was adjusted to 2.1 with concentrated phosphoric acid prior to adding a prescribed volume of methanol ( 0.41 per liter of solution). A UV detector was employed operating at a wavelength of $256 \mathrm{~nm}$.

\section{Batch experiments: soluble enzyme}

The reaction was carried out in a stirred-tank reactor with a reaction volume of $25 \mathrm{ml}$ kept at a constant temperature of $30^{\circ} \mathrm{C}$ and $\mathrm{pH}$ maintained at 6.25 by means of controlled addition of $1 \mathrm{M} \mathrm{NaOH}$ solution. The enzyme concentration was $0.24 \mathrm{~g}^{-1}$ and the substrate concentrations were $200 \mathrm{mmol} 1^{-1}$ for DL-PAPE and 2,000 $\mathrm{mmol}^{-1}$ for 1,4-butanediol. The reaction was initiated with the addition of $\alpha$-chymotrypsin dissolved in a small amount of water. Aliquots of the reaction mixture were taken, diluted with the HPLC eluent, which stopped the reaction, and analyzed by HPLC.

\section{Batch experiments: immobilized enzyme}

The procedure used was similar as for the soluble enzyme with the difference that the immobilized enzyme was introduced into the reactor by using a truncated 2.0-ml polypropylene syringe. This procedure was found to be the most reliable compared to weighing the catalyst wet or after drying, which would destroy the activity. To get reproducible results, immobilized enzyme from the same lot of preparation was used for all experiments. The specific activity of the catalyst was stable within the period of about 3 weeks needed for the experimental study.

\section{Continuous experiments}

A schematic diagram of the experimental apparatus is given in Figure 1. The reactor was a stainless steel column with a diameter of $4.6 \mathrm{~mm}$ and a height of 250 $\mathrm{mm}$. The temperature was maintained at $30^{\circ} \mathrm{C}$ using a plastic jacket for water circulation. Two stainless steel filters, one at the bottom and one at the top of the column, kept the catalyst in place. The porosity of the bed was found to be 0.47 . The substrate solution was heated to $30^{\circ} \mathrm{C}$ by passing through a heat exchanger located upstream to the reactor. A piston pump (MPL E1 SS 5C, Ismatec, $\mathrm{CH}$ ) allowed flow rates ranging from 1 to $10 \mathrm{ml} \mathrm{min}^{-1}$. For each new flow rate, steady state was achieved after a volume of feed solution equivalent to 5 times the reactor space-time had passed through the reactor. Samples were taken with the $\mathrm{pH}$ measured and the composition analyzed by HPLC.

\section{Results}

The $\alpha$-chymotrypsin-catalysed transesterification of a racemic mixture of phenylalanine propyl ester with $1,4-$ 
Transesterification of phenylalanine: $C$. Moresoli et al.

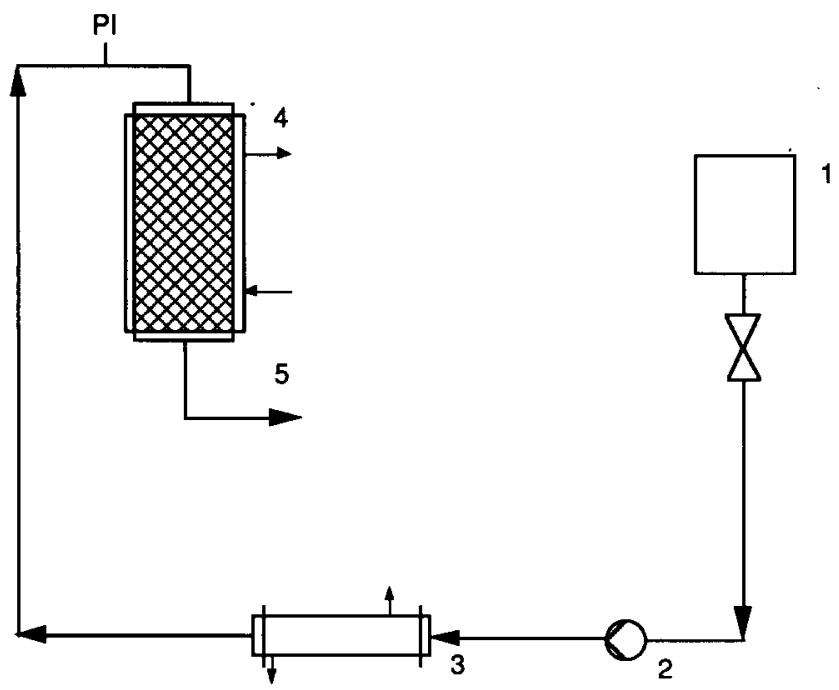

Figure 1 Schematic diagram of the experimental set-up for continuous fixed bed reactor operation. $1=$ feed tank ( 2 liters); 2 = piston pump (MPL E1 SS 5C, Ismatec); 3 = heat exchanger; 4 = fixed bed reactor; 5 = exit stream

butanediol is a complex system. The composition of the mixture and a simplified reaction scheme are illustrated in Figure 2. The reaction proceeds in two steps. The first step is the formation of an intermediate composed of the acyl moiety of the substrate attached to the enzyme with the release of the alcohol. The second step is the decomposition of the acyl-enzyme intermediate by the action of a nucleophile resulting in the product. Three nucleophiles are present, giving rise to three parallel reactions and the formation of three products. The nucleophile 1,4-butanediol gives the desired transfer product, L-phenylalanine 4-hydroxybutyl ester (L-PABE); propanol leads to the formation of the original substrate, L-phenylalanine propyl ester (L-PAPE); and water gives the hydrolysis product, L-phenylalanine (L-PA). Also present is a consecutive reaction due to L-PABE being subjected to forming an acyl-enzyme intermediate as well. This reaction is responsible for the presence of a maximum in the yield of L-PABE as a function of time. The D-form of PAPE participates in the reaction as a competitive inhibitor. Details of the reaction mechanism are discussed in a previous publication. ${ }^{6}$

The evolution of the product yields at constant $\mathrm{pH}$ for the soluble and the immobilized enzyme in a stirredtank batch reactor is illustrated in Figure 3. The yield/ time profiles, shown as continuous lines in Figure 3, and the subsequent figures were simply constructed from inverse polynomial expressions fitted to the data. Figure 3 shows that the yield of the transesterification product in case of the immobilized enzyme is also characterized by a maximum, but its evolution with time differs from that for the soluble enzyme. The maximum yield of the transfer product is lower than that for the soluble enzyme. The yield of the hydrolysis product is higher for the immobilized enzyme than for the soluble enzyme during the entire reaction period.

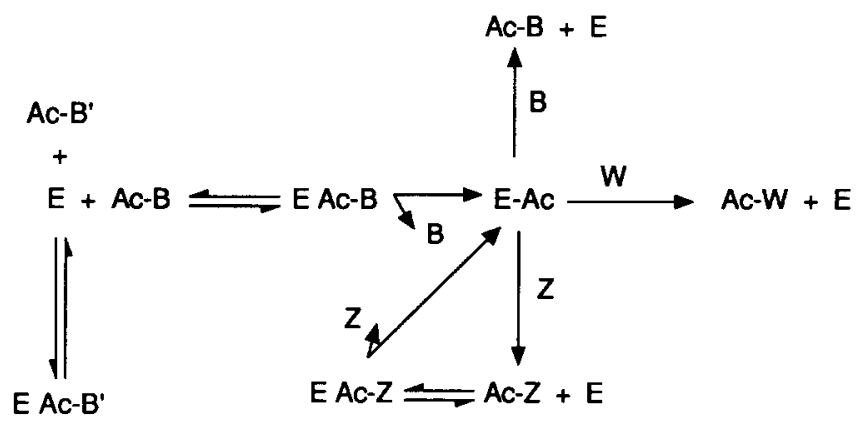

Figure 2 Schematic diagram of the supposed reaction mechanism of $\alpha$-chymotrypsin ${ }^{6} \mathrm{E}$ : enzyme; Ac-B: L-phenylalanine propyl ester; Ac-B': D-phenylalanine propyl ester; Ac-Z: L-phenylalanine 4-hydroxybutyl ester; Ac-W: L-phenylalanine; E-Ac: acyl enzyme intermediate; $E$ Ac-B: enzyme-substrate complex, substrate: L-phenylalanine propyl ester; E Ac-Z: enzyme-substrate complex, substrate: L-phenylalanine 4-hydroxybutyl ester; $W$ : water; Z: 1,4-butanediol; B: propanol

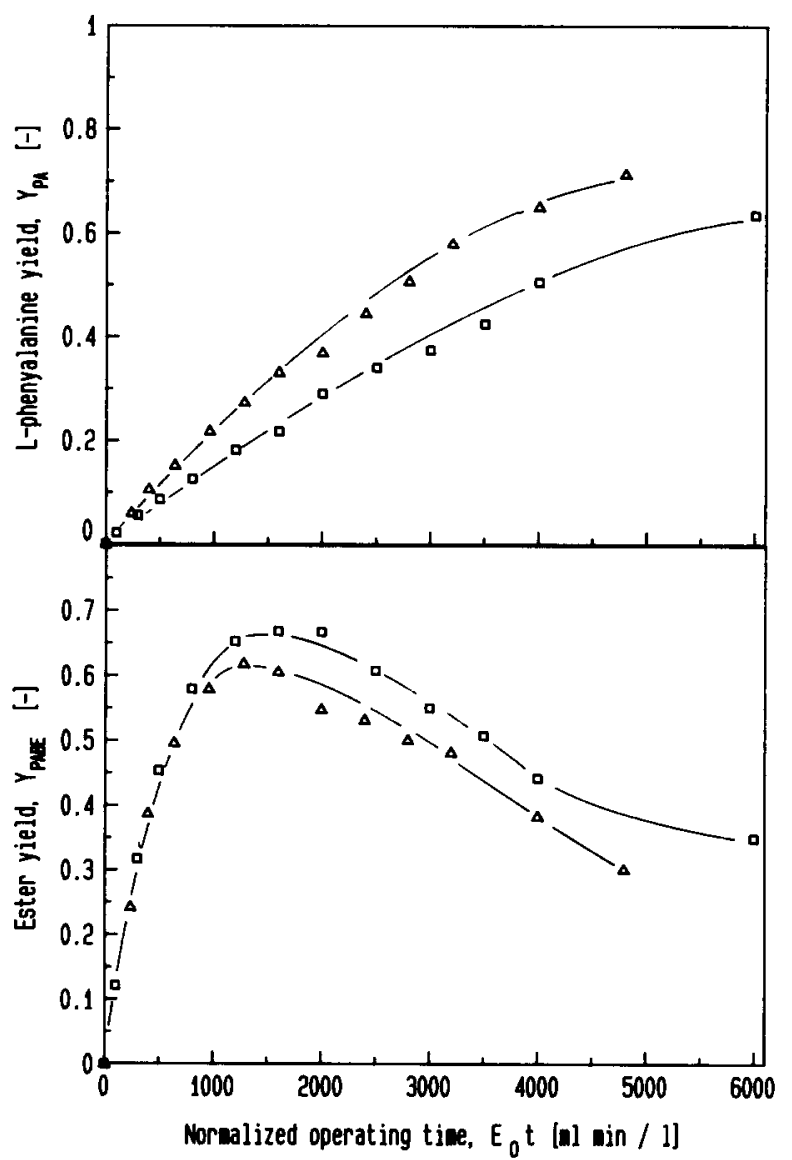

Figure 3 Transesterification reaction at constant $\mathrm{pH}$ (with $\mathrm{pH}$ control) for soluble and immobilized $\alpha$-chymotrypsin (1 ml immobilized $\alpha$-CT set equal to $0.24 \mathrm{mg}$ soluble $\alpha$-CT; see Enzyme activity). DL-Phenylalanine propyl ester: $200 \mathrm{mmol}^{-1}$. 1,4-Butanediol: $2,000 \mathrm{mmol}^{-1}$. ( $\square$ ) Soluble enzyme; $(\Delta)$ immobilized enzyme 


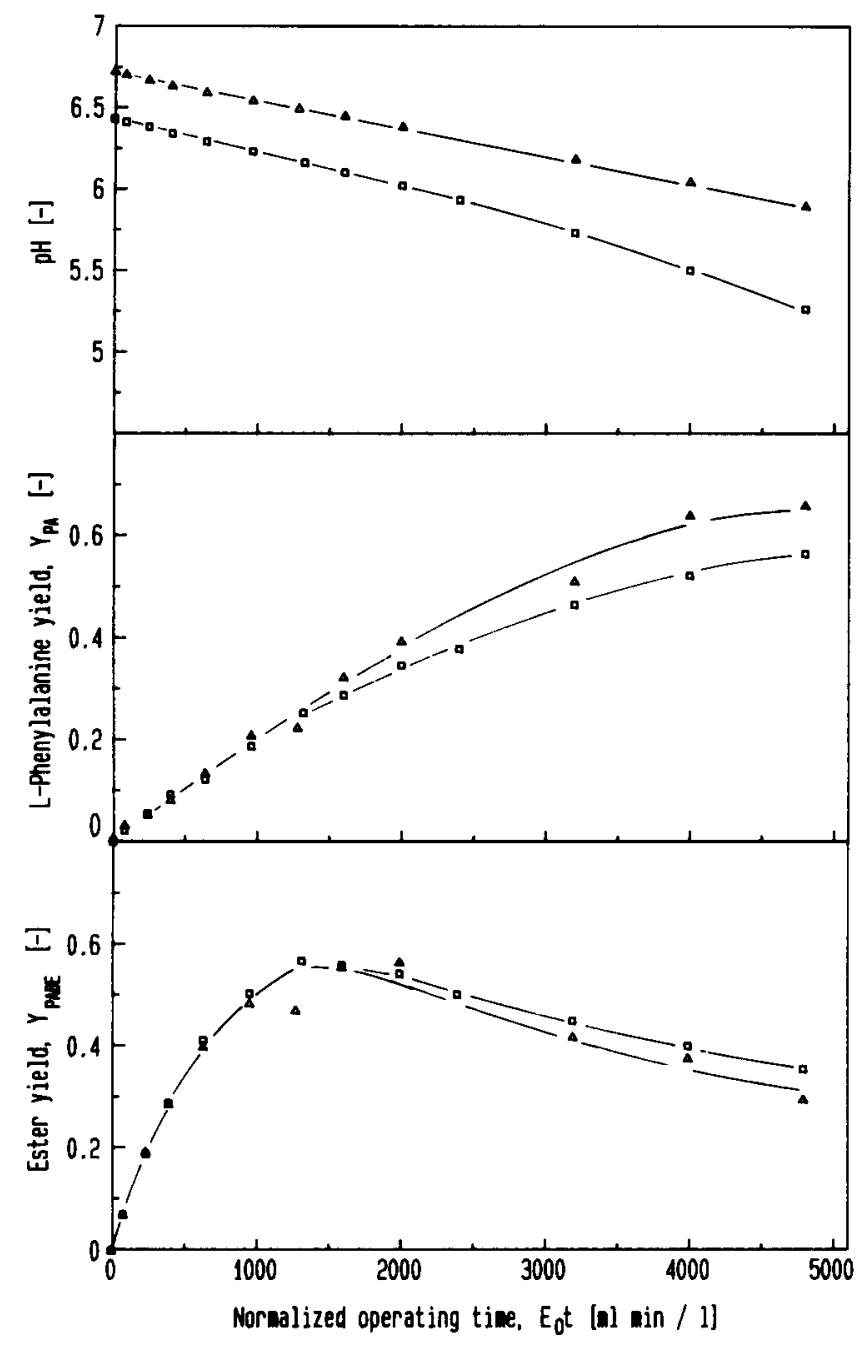

Figure 4 Transesterification reaction catalysed by immobilized $\alpha$-chymotrypsin without $\mathrm{pH}$ control in batch reactor. DL-Phenylalanine propyl ester: $200 \mathrm{mmol}^{-1}$. 1,4-Butanediol: 2,000 $\mathrm{mmol} \mathrm{I}^{-1}$. ( $(\square)$ Initial $\mathrm{pH}: 6.4 ;(\Delta)$ initial $\mathrm{pH}: 6.7$

The transesterification reaction without $\mathrm{pH}$ control is illustrated in Figure 4. The initial pH values, 6.4 and 6.7 , are chosen to operate the system at a $\mathrm{pH}$ as close as possible to $\mathrm{pH} 6.25$, the optimum $\mathrm{pH}$, considering that the hydrolysis reaction produces a $\mathrm{pH}$ drop. It has to be mentioned that the $\mathrm{pK}_{\mathrm{a}}$ of the free amino group of L-PAPE is about 7.05 at $30^{\circ} \mathrm{C}$. The evolution of the product yields with time is very similar at both initial $\mathrm{pH}$ values. The maximum yield of the transesterification product is 0.57 and 0.62 for the reaction with an initial $\mathrm{pH}$ of 6.7 and 6.4 , respectively. The maximum in case of an initial pH of 6.4 is observed in the shortest normalized operating time. The $\mathrm{pH}$ profiles at both initial $\mathrm{pH}$ values are similar. At maximum yield, the $\mathrm{pH}$ is 6.38 and 6.18 for the reaction, with initial $\mathrm{pH}$ values of 6.7 and 6.4 , respectively. These observations are used to select the initial $\mathrm{pH}$ of the feed solution in the continuous fixed bed reactor. $\mathrm{A} \mathrm{pH}$ of 6.4 is chosen, because the highest maximum yield of the transesteri-

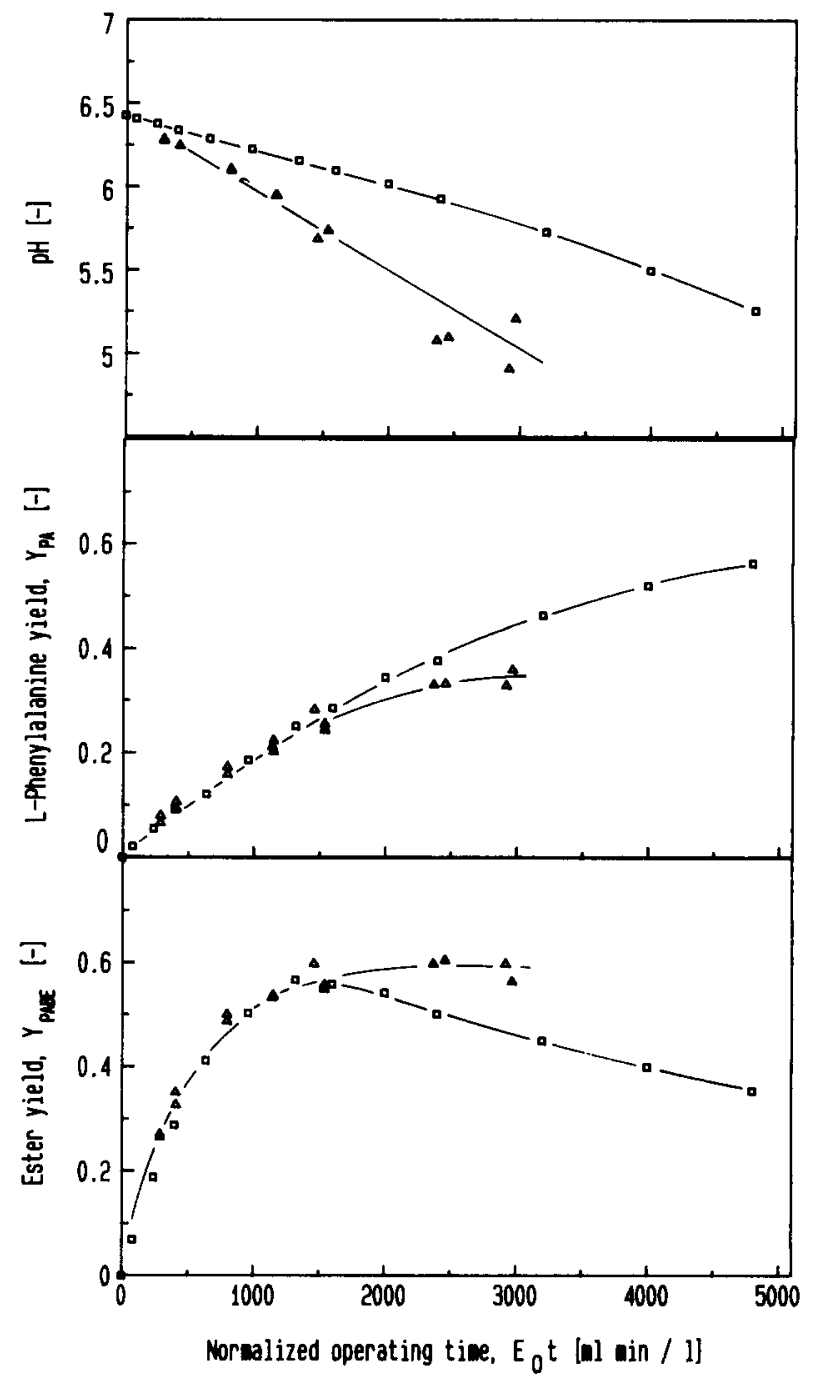

Figure 5 Transesterification reaction catalysed by immobilized $\alpha$-chymotrypsin without $\mathrm{pH}$ control in batch and continuous reactor. DL-Phenylalanine propyl ester: $200 \mathrm{mmol} \mathrm{I}^{-1}$. 1,4-Butanediol: $2,000 \mathrm{mmol} \mathrm{I}^{-1} .(\square)$ Batch reactor; $(\Delta)$ continuous fixed bed reactor

fication product is obtained in the shortest normalized operating time at a mean $\mathrm{pH}$ the closest to 6.25 .

The results of the transesterification experiments carried out in the continuous fixed bed reactor at various flow rates are gathered in Figure 5. No maximum is observed in the evolution of the yield of the transfer product. Similar product yields are observed in both systems for short normalized operating/space-times. Differences appear at low flow rates, equivalent to high normalized operating/space-times. In the continuous system, the yield of the transesterification product remains constant, while in the batch system, it decreases with increasing operating time, as expected. The yield of the hydrolysis product is always lower in the continuous system than in the batch system, whereas the $\mathrm{pH}$ drop is much steeper in the continuous system than in the batch system. For the batch system, the sum of the 
yields of the hydrolysis product and the transesterification product equals the substrate conversion throughout the whole reaction period. In the continuous system, however, the identity only holds for short spacetimes. At lower flow rates, that is, at higher normalized space-times, the sum of the yields is less than the conversion of the substrate by about $10 \%$, indicating that aminolysis may have occurred as another competing reaction.

\section{Discussion}

A comparison of the evolution of the product yields during batch reactor operation shows that the global kinetics differ for the soluble and the immobilized enzyme. The yield of the transfer product for the reaction catalysed by immobilized $\alpha$-chymotrypsin is still characterized by a maximum. A lower yield of the transfer product together with a higher yield of the hydrolysis product is observed for the immobilized enzyme, suggesting mass transfer limitations inside the porous catalyst. Accumulation of the transfer product inside the catalyst particle giving rise to further hydrolysis of this product is suspected.

For the reaction carried out without $\mathrm{pH}$ control, a drop in $\mathrm{pH}$ is observed as a consequence of hydrolysis. Within the domain of initial $\mathrm{pH}$ values considered, 6.4 and 6.7 , the product yields are similar. The maximum yield of the transfer product is 0.62 at a pH of 6.18 , and 0.58 at a $\mathrm{pH}$ of 6.38 .

The continuous fixed bed reactor proves to be an appropriate system for transesterification. At the former optimized operating conditions for obtaining a maximum productivity at $95 \%$ of the maximum yield of the transfer product, ${ }^{6}$ a productivity of $64.9 \mathrm{~mol}$ $\mathrm{d}^{-1} 1^{-1}$, referred to the total catalyst volume, is achieved. The yields and the $\mathrm{pH}$ profiles observed in the continuous system compare reasonably well with those obtained in the batch system until the maximum yield of the transfer product is reached during batch operation. From then onward, the yield in case of continuous operation remains constant. Since the maximum yield is almost equal in both cases, this fact is even advantageous from a practical point of view, because the flow rate does not have to be controlled rigorously. A plausible explanation for this finding may be derived from the facts that the conversion of the substrate is higher than the sum of the yields of the hydrolysis product and the transesterification product in case of the continuous system, and a more pronounced $\mathrm{pH}$ drop is observed for continuous operation. These differences suggest the presence of an additional reaction producing hydronium ions. A close look at the composition of the reaction mixture indicates that the L-form of PAPE and that of PABE as well may also act as nucleophiles due to their free amino groups, leading to the formation of an esterified dipeptide. Although the necessary unprotonated form of the amino group will be small in terms of concentration, an accumulation of L-PABE as a result of additional film diffusion resistance at low flow rates could result in dipeptide formation leading to an additional drop of $\mathrm{pH}$. This $\mathrm{pH}$ drop seems to be the reason that the reaction does not proceed any further. Thus, the formation of the dipeptide could explain the lower yield of the hydrolysis product in contradiction to the more pronounced $\mathrm{pH}$ drop observed in the continuous reactor. The formation of such a byproduct, a dipeptide of the ester, has been identified (Flaschel et al. ${ }^{8}$ ) as a major problem during optical resolution of phenylalanine by ester hydrolysis of the DL-phenylalanine propyl ester with $\alpha$-chymotrypsin.

\section{Acknowledgement}

This study was supported by the Swiss National Science Foundation

\section{Nomenclature}

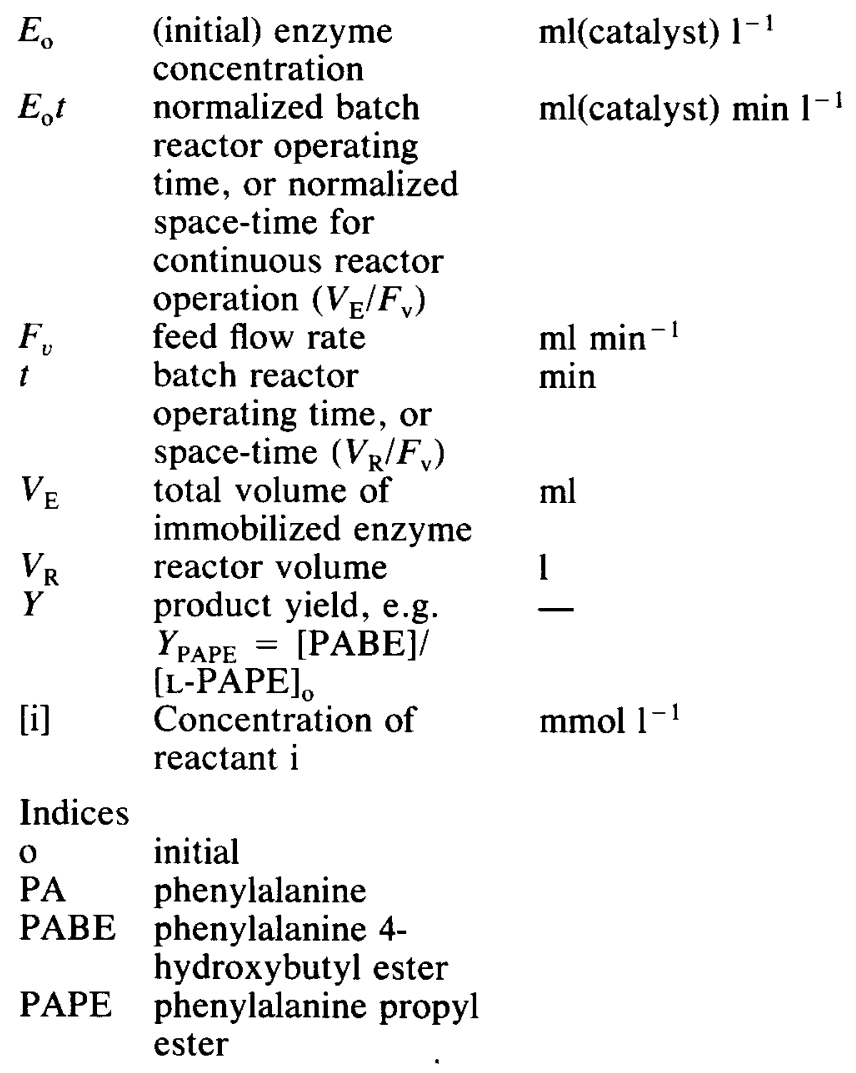

\section{References}

1 Tramper, J., van der Plas, H. C. and Linko, P. (eds.) Biocatalysts in Organic Syntheses. Proceedings of the International Symposium. Stud. Org. Chem. 22, 1985

2 Goldstein, L. Methods Enzymol. 1977, 44, 397-443

3 Kasche, V. Enzyme Microb. Technol. 1986, 8, 4-16

4 Kasche, V., Galunsky, B., Haufler, U. and Zöllner, R. in Enzyme Technology (Lafferty, R. M., ed.) Springer-Verlag, Heidelberg, 1983, pp. 297-308

5 Flaschel, E., Moresoli, C. and Renken, A. Dechema Biotechnology Conferences, 1990, 4, 423-430

6 Moresoli, C., Flaschel, E. and Renken, A. Biocatalysis 1990 (in press)

7 Keller, R. Verfahren zur Herstellung aromatisch substituierter L-Aminosäuren, 1984, E.P. 178553 A2, 18.10.84

8 Flaschel, E., Crelier, S. and Renken, A. Ann. NY Acad. Sci. $1988,542,219-223$ 